\title{
NITRILES AS SOLVENTS IN MOLECULAR WEIGHT DETERMINATIONS
}

BY LOUIS KAHLEXBERG

Nitriles have rarely been used as solvents in making molecular weight determinations. In I897 Werner ${ }^{\mathrm{I}}$ determined the molecular weight of mercuric chloride, mercuric iodide and silver nitrate in benzonitrile by the ebullioscopic method, and this was the only case that I could find in the literature where a nitrile had been used as solvent. Werner determined the so-called molecular elevation of the boiling-point for this solvent empirically by using diphenylamine as solute and assuming its molecular weight to be that computed from its formula. In this way he obtained 36.5 as the constant for benzonitrile. According to the Trouton-Schiff rule, Werner calculated the constant to be 45.79 ; he states clearly that he is unable to explain the discrepancy. Recently the latent heat of evaporation of benzonitrile has been carefully measured by Longuinine ${ }^{2}$ and also by myself. ${ }^{3}$ The results of these investigations are practically identical, the value found being 87.7 . From this value the molecular elevation of the boiling-point, when calculated according to the Arrhenius-Beckmann formula, becomes $\mathrm{K}=\frac{0.02(\mathrm{r} 89+273)^{2}}{87.7}$ or 48.67 , which is the constant that onght to be used in computing the molecular weights. In Table I. are given the results of Werner, recalculated, using this constant. In the table, $s$ represents the amount of solute, $l$ the quantity of solvent, $\Delta$ the observed rise of the boiling-point, and $m$ the molecular weight calculated according to the usual formula.

\footnotetext{
1 Zeit. anorg. Chem, 15, 3I (1897).

${ }^{3}$ Archiv. des Sciences Naturelles de Genève, 9, 5-26 (I899).

${ }^{3}$ Jour. Phys. Chem. 5, 230 (I89I).
} 
TABLE I.

(Solvent benzonitrile)

Diphenylamine $\left(\left(\mathrm{C}_{6} \mathrm{H}_{5}\right)_{2} \mathrm{NH}\right.$, mol. wt. $\left.=\mathrm{I} 69\right)$

\begin{tabular}{|c|c|c|c|}
\hline$s$ & $l$ & $\Delta$ & $m$ \\
\hline O. 1298 & $20.1 \mathrm{I}$ & 0.135 & 233 \\
\hline 0.2357 & 20. II & 0.250 & 228 \\
\hline O. I IO4 & 14.45 & 0.169 & 220 \\
\hline \multicolumn{4}{|c|}{ Mercuric chloride $\left(\mathrm{HgCl}_{2}\right.$, mol. wt. $\left.=27 \mathrm{I}\right)$} \\
\hline 0.2123 & 9.45 & 0.126 & $42 \mathrm{I}$ \\
\hline 0.5446 & 19.45 & 0.358 & $3^{80}$ \\
\hline 0.3738 & 21.68 & 0.280 & 300 \\
\hline 0.8710 & 21.68 & 0.585 & 335 \\
\hline \multicolumn{4}{|c|}{ Mercuric iodide ( $\mathrm{HgI}_{2}$, mol. wt. $\left.=454\right)$} \\
\hline 0.1737 & 23.92 & $0.06 \mathrm{I}$ & 580 \\
\hline 0.5135 & 23.92 & 0.153 & 684 \\
\hline \multicolumn{4}{|c|}{ Silver nitrate $\left(\mathrm{AgNO}_{3}\right.$, mol. wt. $\left.={ }_{17} \mathrm{O}\right)$} \\
\hline 0.3534 & 23.74 & 0.345 & 220 \\
\hline 0.8336 & 23.74 & 0.750 & 239 \\
\hline O. 1874 & 23.50 & 0.160 & 243 \\
\hline 0.4326 & 23.50 & 0.380 & 236 \\
\hline
\end{tabular}

Table II. gives a series of determinations of my own. The sample of benzonitrile used was the same as that employed in making the measurement of the latent heat of evaporation.

TABLE II.

(Solvent benzonitrile)

Silver nitrate $\left(\mathrm{AgNO}_{3}\right.$, mol. wt. $\left.=170\right)$

\begin{tabular}{c|c|cc}
\hline$s$ & \multicolumn{1}{c}{} & $\Delta$ & $m$ \\
\hline 0.1098 & I6.6I & 0.130 & 248 \\
0.3352 & I6.6I & $0.38 \mathrm{I}$ & 258 \\
0.5208 & I6.6I & 0.590 & 259
\end{tabular}

In the case of acetonitrile I found the latent heat of evaporation to be 173.6 . The value obtained by Louguinine is r7o.68. According to the former value the boiling-point constant becomes $\frac{0.02(80.5+273)^{2}}{\mathrm{I} 73.6}$, or I 4.39 ; while according to the 
latter value it equals $\mathrm{I}_{4} \cdot 63$. In making the computations in Table III., the constant I 4.39 was used. The sample of acetonitrile employed was the same as that used in making the determination of the latent heat of evaporation. The solutes used were, with the exception of the silver nitrate, of Kahlbaum's manufacture. They were naphthalene, melting-point $80^{\circ}$; diphenyl, melting-point $69-69.5^{\circ}$; and diphenylamine, meltingpoint $54^{\circ}$. The silver nitrate was obtained from Baker \& Adamson, and was thoroughly dried. The symbols in Table III. have the same significance as those in the preceding tables.

TABLE III.

(Solvent acetonitrile)

Naphthalene $\left(\mathrm{C}_{10} \mathrm{H}_{8}\right.$, mol. wt. $=\mathrm{I} 28$

\begin{tabular}{cccc}
$s$ & $l$ & $\Delta$ & $m$ \\
\hline 0.3103 & I I.04 & 0.280 & I 44 \\
0.5153 & I I.04 & 0.469 & 143 \\
0.7910 & II.04 & 0.717 & 144 \\
0.9952 & II.04 & 0.905 & 143
\end{tabular}

Diphetyly $\left(\mathrm{C}_{12} \mathrm{H}_{10}\right.$, mol. wt. $\left.=\mathrm{I} 54\right)$

\begin{tabular}{|c|c|c|c|}
\hline & & & \\
\hline 0.2208 & I I. 25 & 0.165 & 171 \\
\hline 0.3246 & I I. 25 & 0.242 & 172 \\
\hline 0.5494 & I I 25 & $0.42 \mathrm{I}$ & 167 \\
\hline 0.8374 & I 1.25 & 0.673 & I 59 \\
\hline \multicolumn{4}{|c|}{ Diphenylamine $\left(\left(\mathrm{C}_{6} \mathrm{H}_{5}\right)_{2} \mathrm{NH}\right.$, mol. wt. $\left.-\mathrm{I}_{69}\right)$} \\
\hline O. I $64 \mathrm{I}$ & 11.29 & 0.168 & I 25 \\
\hline 0.5314 & I I . 29 & 0.549 & I 24 \\
\hline 0.6838 & I I . 29 & 0.679 & I 28 \\
\hline 0.8735 & I I. 29 & 0.833 & I 33 \\
\hline \multicolumn{4}{|c|}{ Silver nitrate $\left(\mathrm{AgNO}_{3}\right.$, mol. wt. $\left.=\mathrm{I} 7 \mathrm{O}\right)$} \\
\hline o. 1856 & 10.99 & 0.180 & I 35 \\
\hline 0.3050 & 10.99 & 0.298 & I 34 \\
\hline 0.5397 & 10.99 & $0.5 \mathrm{IO}$ & I 38 \\
\hline 0.7977 & 10.99 & 0.760 & 138 \\
\hline I.0350 & 10.99 & 0.939 & I 44 \\
\hline
\end{tabular}

If the constant calculated from Louguinine's value for the latent heat of vaporization had been used, the molecular weights 
in Table III. wotld have been I. 8 percent higher. As the boiling-point constant of acetonitrile is nearly 2.8 times that of water, the molecular weights in the former solvent are more readily determined with accuracy.

The attempt was made to use propionitrile as a solvent for molecular weight determinations, but it was unsuccessful, inasmuch as in spite of all exertions, it was found impossible to secure a sample of the substance that had a sufficiently constant boiling-point. The same difficulty was met in trying to employ butyronitrile and valeronitrile.

From Tables I. and II. it appears that the molecular weights of the solutes in benzonitrile are all considerably higher than the theoretical values, without, however, reaching a figure corresponding to a double molecule. The mercuric chloride, mercuric iodide and silver nitrate solutions in benzonitrile are fairly good electrolytes; while the solution of diphenylamine in this solvent is a non-electrolyte. From the boiling-point results in the tables one could clearly not have foretold these facts.

Turning now to Table III. we see that naphthalene and diphenyl yield molecular weights higher than the theoretical. The solutions of these substances in acetonitrile are non-electrolytes. Again, diphenylamine, which is also a non-electrolyte when dissolved in acetonitrile, yields an abnormally low molecular weight. ${ }^{\mathrm{I}}$ In fact the molecular weight of this solute is lower than that of silver nitrate, althongh the latter substance when dissolved in acetonitrile is an electrolyte par excellence.

A comparison of the results obtained with diphenylamine and silver nitrate is of special interest, because these two substances have practically the same theoretical molecular weight. Though the solutions of diphenylamine in both benzonitrile and acetonitrile are non-electrolytes, and the solutions of silver nitrates in these solvents are good electrolytes, yet in both solvents these solutes behave practically alike. This then is a striking illustration that there is no such simple relation between the

${ }^{1}$ Reference has been made to this fact on a previous occasion. Compare Jour. Phys. Chem. 5, 344 (Igor). 
boiling-points of solutions and their electrical conductivity as the theory of Arrhenius claims. ${ }^{\mathrm{x}}$

At any given pressure, the boiling-point of a solution is determined by the concentration and by the chennical character of the solvent and solute, which determines the mutual attraction existing between them. This mutual attraction is the essence of the so-called osmotic pressure and is the cause of the process of solution. In applying the gas laws to solutions, we do at times get molecular weights for the solute that are equal to the theoretical within the limit of error of experimeut; but more frequently we do not, and this regardless as to whether the solutions are electrolytes or not, as is well shown by the solutions in these nitriles.

It is probable that the high molecular weights in benzonitrile are partly, if not largely, due to the relatively high boiling-point of the solvent $\left(\mathrm{I} 89^{\circ}\right)$. In acetonitrile the molecular weights are much lower. Its boiling-point is $80.5^{\circ}$. Examples of this kind are not uncommon; and I hope to recur to this point ere long in the course of a more general consideration of the subject of solutions.

Laboratory of Physical Chemistry, Unizersity of Wisconsin. Madison, Wis., Dec. 5, Igor.

${ }^{1}$ In the case of silver nitrate when dissolved in acetonitrile, the so-called degree of electrolytic dissociation corresponding to the molecular weight 135 (Compare Table III.) is 26 percent; from the conductivity determinations of Dutoit and Friderich (Bu11. Soc. Chim. Paris, (3) 19, 327 (1898)) it is about 34 percent for approximately the same concentration. To be sure, this comparison is not quite fair, as we are not comparing the solutions at the same temperature : but the discrepancy would very likely not disappear even if the comparison were made at the same temperature. Compare Jour. Phys. Chem. 5, 339 (19or). 